Tetik, M., Peltokorpi, A., Seppänen, O., Viitanen, A., and Lehtovaara, J. (2019). "Combining Takt Production with Industrial Logistics." In: Proc. $27^{\text {th }}$ Annual Conference of the International. Group for Lean Construction (IGLC), Pasquire C. and Hamzeh F.R. (ed.), Dublin, Ireland, pp. 299-310. DOI: https://doi.org/10.24928/2019/0156. Available at: 〈www.iglc.net>.

\title{
COMBINING TAKT PRODUCTION WITH INDUSTRIALIZED LOGISTICS IN CONSTRUCTION
}

\author{
Müge Tetik ${ }^{1}$, Antti Peltokorpi ${ }^{2}$, Olli Seppänen ${ }^{3}$, Ari Viitanen ${ }^{4}$, and Joonas \\ Lehtovaara $^{5}$
}

\begin{abstract}
Construction industry has recently widely adopted takt production which stabilizes the production rhytm and improves flow of site operations. Based on the factory physics, it is known that when production flow is increased, external variation which can disturb the production should be eliminated simultaneously. Inappropriate material deliveries cause remarkable external variation and waste in construction operations. However, the reported studies of the takt production do not discuss in depth of the role of logistics and external variation. The purpose of this research is to investigate how takt production benefits from proper logistics solution. In practice, we explore the role of logistics in two project industries, shipyard and construction, in which takt production is implemented. The findings reveal improvements with regards to utilizing specific assembly and logistics units together with JIT delivery of material kits and integrated design and production information. In fact, results showed a reduction in the material waste and procurement costs as well as increase in the production rate in both industries but with different extent. The value of this research for practice and academia is that takt results improve when implemented with specific logistic solutions. Future research should investigate the impact of logistics in takt with using case studies and focusing on construction operations.
\end{abstract}

\section{KEYWORDS}

Takt production, logistics, lean construction, industrialized logistics.

Doctoral Candidate, Dept. of Civil Enginering, Aalto University, Espoo, Finland, muge.tetik@aalto.fi

2 Assistant Professor, Dept. of Civil Enginering, Aalto University, Espoo, Finland, antti.peltokorpi@aalto.fi

3 Professor of Practice, Dept. of Civil Enginering, Aalto University, Espoo, Finland, olli.seppanen@aalto.fi

$4 \quad$ Chairman of the Board, Carinafour, Turku, Finland, ari.viitanen@c4.fi

5 Doctoral Candidate, Dept. of Civil Enginering, Aalto University, Espoo, Finland, joonas.lehtovaara@aalto.fi 


\section{INTRODUCTION}

Construction industry has recently started to adopt takt production which originates from manufacturing industries. Takt is a lean concept which attempts to enable continuous flow and increase stability in production processes. The production proceeds with the same rhythm and the flow of the product is enabled by causing all the tasks to be grouped and balanced to a calculated takt time (Pattanaik and Sharma 2008). Takt time is the unit of time in which a product must be manufactured in order to match the rate that this product is demanded (Hopp and Spearman 2004). Using takt production displays huge improvements in productivity, quality and project lead time while decreasing the amount of work-in-progress, as in the case of ship cabin refurbishment production (Heinonen and Seppänen 2016). In the case of hospital construction, a project with takt production was completed six months ahead of its planned schedule (Linnik et al. 2013). 70\% reduction in construction duration was identified by Binninger et al. (2018).

However, it has been claimed that takt production system is more vulnerable if there is variability in the process (Seppänen 2014). Material logistics is an important factor causing variability because availability of the materials effects the execution of activities and complexity is increased when material delivery dates fluctuate (Hamzeh et al. 2007). Supply of materials is a good example of external variation, which refers to factors which are not absolutely regular and predictable and which therefore present variability for the production, such as irregular demand, product variety to meet market needs, interrupting operations to satisfy specific customer (Hopp and Spearman 2004), resource changes, machine malfunction, rushing orders, transport breakdowns and supplier related problems (Viswanadham and Raghavan 1997). According to Kingman's formula (1961), external variation or resource utilization must be reduced when adopting a single piece flow. If the flow efficiency is increased without reducing the variation, the resource needs to be increased exponentially, which is difficult to ensure in practice.

Problems in material flow are major sources for external variation in construction operations. Arbulu and Ballard (2004) mentioned that the demand and supply variability directly effects the project performance, decreases quality and safety while increasing cost and duration. Especially when takt is utilized, challenges can arise, such as communicating the production plan and commitment of the project partners and material deliveries to the takt schedule (Frandson et al. 2013). Vatne and Drevland (2016) mentioned the delivery of doors from the manufacturer in a construction project adopting takt production were the reason behind a delay in completing work packages. Thus, material availability can effect the project duration and flow of operations when takt is used. On the other hand, material stockpiles on-site impact the available space and can interfere with the productivity (Seppänen and Peltokorpi 2016). Without JIT technique used in material delivery and handling, workers' productivity may decrease due to waiting or sorting the congested materials on-site (Ghanem et al. 2018). Providing all the required materials in the right moment and location can be a solution to ensure flow and productivity of operations. The successful takt implementation and continuous flow rely on careful planning and daily control of production (Tommelein 2017). Productivity increase is possible when construction process is planned from a logistics perspective to manage the material flow 
(Agapiou et al. 1998). Using proper centralized logistics management along with takt production, waste due to material and information handling problems can be solved.

Logistics is managing procurement, movement and storage of materials and the related information flows to maximize profitability with cost-effective fulfilment of orders (Christopher 2016). In the construction industry, advanced logistics solutions are gaining popularity not only to optimize material flow but also to improve productivity and flow of assembly operations on-site (Seppänen and Peltokorpi 2016). Studies indicate positive results when implementing different logistics solutions in construction, such as assembly kitting in the consolidation center and delivery with JIT (Tetik et al. 2018), real time material tracking (Zhao et al. 2017) and on-site shops (Tanskanen et al. 2015). Adopting a proper logistic solution can shorten the construction time, reduces the overall project cost, saves workers' time on site and decreases the need for storage which leads to savings (Knaack et al. 2012). Dedicated logistics resources on-site prevent inefficiencies in work and therefore increase the utilization of the site resources (Sundquist et al. 2018).

Despite the obvious role of a proper logistic solution in decreasing harmful external variation in takt production, none of the reported empirical studies of takt production discuss in depth the role of logistics and external variations. Thus, there is a need for practical knowledge about the role and impacts of logistics solutions when applying takt in construction projects. The purpose of this research is to investigate how takt production benefits from proper logistics solution. In practice, we explore the role of logistics in two project industries, shipyard and construction, in which takt production is implemented. The reason to explore those two industries is that more mature applications of takt and logistics solutions are adopted in the shipyard industry and it would be helpful to identify issues and potential solutions in the more fragmented construction industry. The contribution of this paper is on the new knowledge of the role of logistics in takt production which has not been specifically studied and documented before in the construction context.

\section{THEORETICAL BACKGROUND}

Theoretically, this research combines two research streams: (1) Logistics solutions in construction area and (2) combining logistics solutions with takt production.

\section{LOGISTICS SOLUTIONS IN CONSTRUCTION}

Logistics solutions are neglected in the construction industry due to problems in project budgets although they improve productivity (Sullivan et al. 2011). There are many logistics solutions used in the construction industry to improve material handling and schedule. Kitting is one of the logistics solutions that can be applied in the construction operations. When products or components are organized, packed and delivered as one package, the term "kitting" is used (Bozer and McGinnis 1992). The idea is that the kit is prepared in a consolidation center and delivered to the place of work.

Just-in-time delivery is a lean concept which means that upon the delivery of materials to construction sites, they are to be installed immediately without being stored (Tommelein and Li 1999). This type of delivery can partially decrease the need for an on-site storage area (Jaillon and Poon 2014) and increase the quality and efficiency (Pheng and Hui 1999). The waste is reduced by delivering the required materials exactly when they are needed. 
Make-to-stock as well as engineer-to-order materials can be procured and delivered on a JIT basis. JIT delivery can be combined with assembly kitting.

Kitting can be combined with just-in-time (JIT) delivery and consolidation centers. Consolidation centers are logistics solutions where the consolidation facilities keep the materials for a period of time till their delivery to the shops or sites on a JIT basis by the logistics workers (Sullivan et al. 2011). Sundquist et al. (2018) suggest that logistics resources such as logistics hubs can be utilized in an efficient manner through expanding of the scale of the operations. Hamzeh et al. (2007) state that consolidation centers can be configured to be used for the purposes such as assembly and kitting as well as consolidation, sorting and breaking the bulks. Tetik et al. (2018) conducted research about the applicability and impacts of kitting in renovation operations revealing promising results.

In the advanced logistics solutions, one typical requirement is that procurement activities are organized in a centralized manner and not by trade contractors. Centralized procurement can strengthen the logistics solutions by procuring materials centrally and delivering them to the consolidation center. Control activities are enhanced by centralized procurement (Clifford et al. 2000). Centralized logistics can be applied through third party logistics (TPL). Using TPL decreases material logistics costs in construction projects (Ekeskär and Rudberg 2016).

\section{COMBINING LOGISTIC SOLUTIONS WITH TAKT PRODUCTION}

In this section, we will discuss how the suggested logistic solutions in construction would fit with takt production in site operations. Vatne and Drevland (2016) mentioned that the logistics is a key aspect for takt planning in residential construction. Implementing several lean concepts together such as kitting, JIT delivery and takt production leads to further improvements. Linnik et al. (2013) mention an attempt to use takt strategy for planning for materials and information where the takt to be used to determine the kitting plan and JIT deliveries in construction context. Takt can motivate the trades to kit and deliver with JIT delivery.

Dallasega et al. (2013) state that to allow JIT delivery of engineer-to-order parts, the production process must be aligned with construction on-site. To ensure the delivery of the parts in the required time, the takt production sequence should be communicated well with every stakeholder and stakeholders should commit to the takt sequence which may not be fully possible in practice. Thus, centralized procurement of the parts and JIT delivery can be a solution to guarantee that the required materials to be available at the right moment.

Even though combination of logistics and takt has not yet been explicitly studied, research on lean in the construction context has partly handled the topic. Already the construction of the Empire State Building included determining the size of work teams and zones to fit a takt rate. Moreover, consolidation centers were used to help ensure a continuous workflow (Jacobsson and Wilson 2018). This provides efficient transportation of the materials and less on-site materials storage along with takt production benefits.

Utilizing takt can bring benefits in renovation projects. Renovation projects perform under schedule pressure where the area which was actively used cannot be used during the 
renovation operations (Alhava et al. 2015). Utilizing assembly kitting and JIT delivery, logistics solution with takt production can be a good fit for renovation projects.

\section{RESEARCH METHOD}

We studied two project industries where takt and logistics are adopted. We analyzed the role of logistics solution in takt production both in construction projects and marine industry projects. By investigating and comparing the role of logistics in the operations of the two industries we were able to identify possibilities how construction industry could obtain more benefits from takt and logistics based on similar and more mature shipyard industry's practices.

The access to data about the projects in both industries was obtained through a Finnish logistics service company which has originally operated in shipyard, but recently widened their offerings to the construction industry. We collected both qualitative and quantitative data for data triangulation. Triangulation is used to test the validity of the work through the convergence of information by different sources (Carter et al. 2014). The data analysis includes the analysis of interviews with the logistics service provider and documents analysis.

The qualitative part of research was carried out by utilizing interviews. The semistructured interview was conducted with the chairman of the logistics service company of the main contractor. Quantitative part of the study includes analysis of the documents obtained from the main contractor.

An alliance-based contract was made between the companies. The contractor company is one of the leading companies in Finland in terms of renovation projects. The logistics company serves the contractor with the Assembly and Logistics Unit (ALU) in which three logistics workers are working for five different construction projects. The contractor company aims to utilize the same solution with all of its pipe renovation projects and they have been using the logistics provider's service for 1,5 years now. In the shipyard industry, the similar ALU is utilized to serve centralized material deliveries to the shipyard.

\section{FINDINGS}

Our findings indicate that using the logistics solution provided by the logistics company when applying takt, results in multiple improvements in projects, including improved procurement quality, less material waste and ability to follow the predetermined takt sequence. The logistics solution referred here is material kitting in the assembly and logistics center (ALU) with JIT delivery while procurement is centralized.

Based on our analysis of the interview data, the reasoning behind using the logistics solution together with takt includes (1) enforcing the production sequence by using single flow strategy, (2) easiness to control the production process, (3) centralizing procurement which leads to material cost savings, and (4) enabling shorter lead times due to controlling variation. Thus, benefits are on improving production on-site, reducing material waste and total material cost and higher flow efficiency with lower throughput times.

In the renovation projects, standard materials are delivered directly to the work site where there is an on-site shop. The rest of the materials are delivered to the ALU, kitted 
and then sent to the work site. Kits are prepared in the ALU and delivered to the worksite 2-3 times a week. Logistics provider makes sure that only the required materials are delivered to the worksite at the required time. The kits are apartment, day and team based. Material process can be seen in Figure 1. From the ALU, the kits are delivered to the site and then to the specific location based on the takt sequence. The same material process was used by the same main contractor in the past. In case of missing materials inside the kits, speed delivery is used to ensure the material availability. Any extra materials are either sent back to the ALU or moved to the next apartment. The latter includes updates on the kits for the next apartment in order to not cause extra materials in the next apartment. The packaging and wrapping materials are cleared out from the locations.

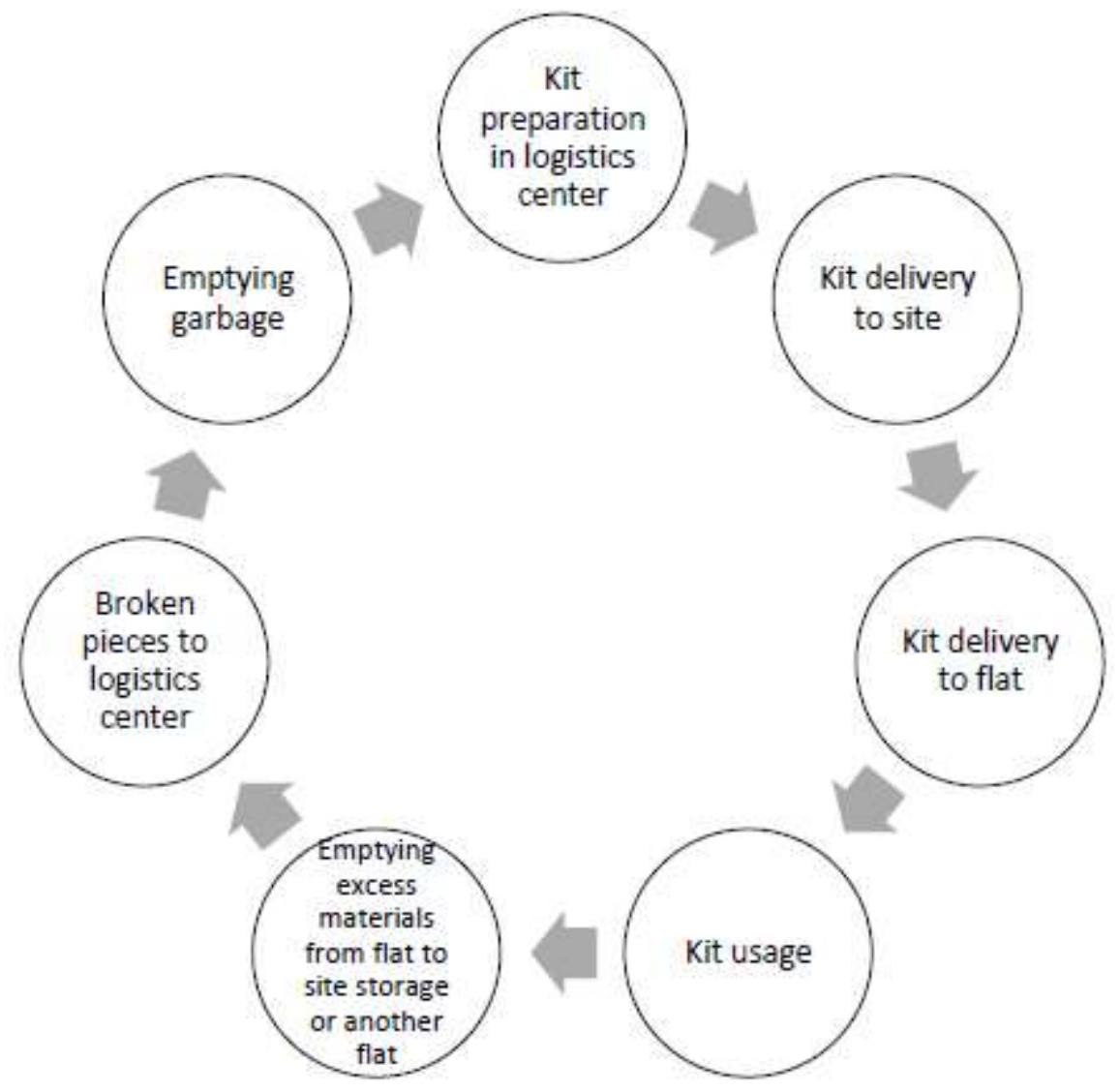

Figure 1: Material process of the logistics provider (Tetik et al. 2018)

In the shipyard industry, all materials are delivered to the ALU and then to the work site as kitted. Material picking and kitting activities take 3 hours in the ALU and delivery is faster because the ALU is closer to the production site. The amount of pre-assemblies is higher in the shipyard industry where fittings and insulation are already done in the ALU. The takt time in the shipyard industry is 40 minutes. The production rate increase is up to $20-40 \%$ with the takt production along with logistics solution and centralized procurement. 
The operations in the ALU are represented in Figure 2. Logistics provider also executes the procurement operation while the contractor company does the sourcing activities. Moreover, the logistics provider does the material inspection to increase the material quality. Procurement is done based on bill of materials (BOM) for each flat. Design process needs to be able to generate BOM per flat and manufacturing BOM where all standard and general parts are listed. The parts in the manufacturing BOM are delivered to the on-site supermarket without going through the ALU while BOM per flat materials are kitted in the ALU and then delivered to the task location. The materials which are not included in the kits include electrical and technical parts. There is a 3-8 days buffer for supplying the materials in the ALU. The communication between the construction site and ALU is continuously done via an online platform through which BOM and schedule changes are sent automatically.

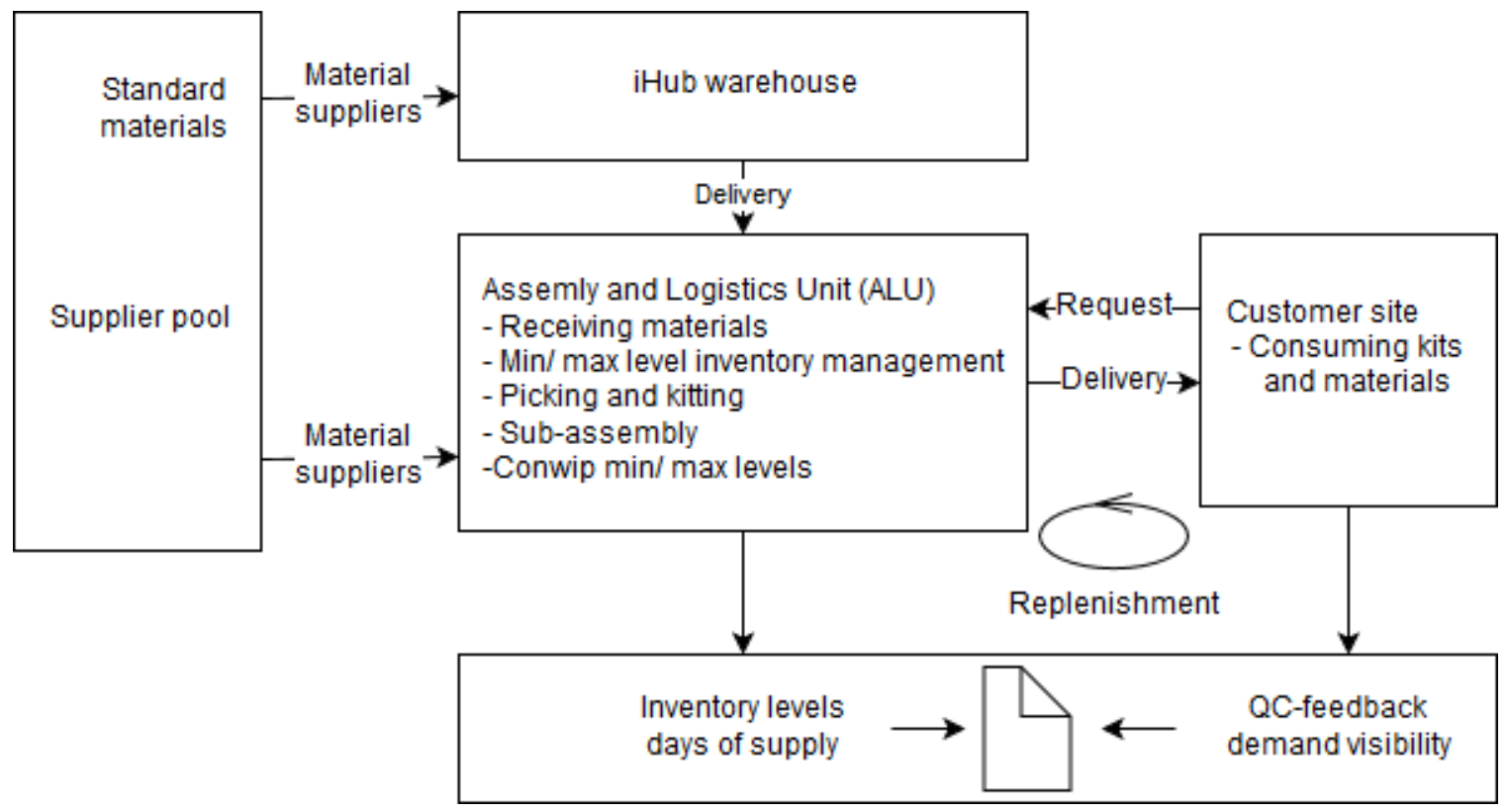

Figure 2: Operations in the ALU

Figure 3 illustrates the basics of the production system of the logistics provider. The logistics provider gets the rough schedule from the contractor 2-3 weeks before the installation starts on the work site. The detailed fixed schedule is available 3 days before the installation of a specific location. This provides enough time for material picking and kitting in the ALU. In the ALU, one day is allocated for picking and kitting the materials.

Three logistics workers work in the ALU. These workers do pre-assemblies of plumbing parts as well as cutting some materials in addition to kitting. Only some plumbing parts are pre-assembled in the ALU. The takt time is one day and the takt area is one apartment and comprises the work of one team. 


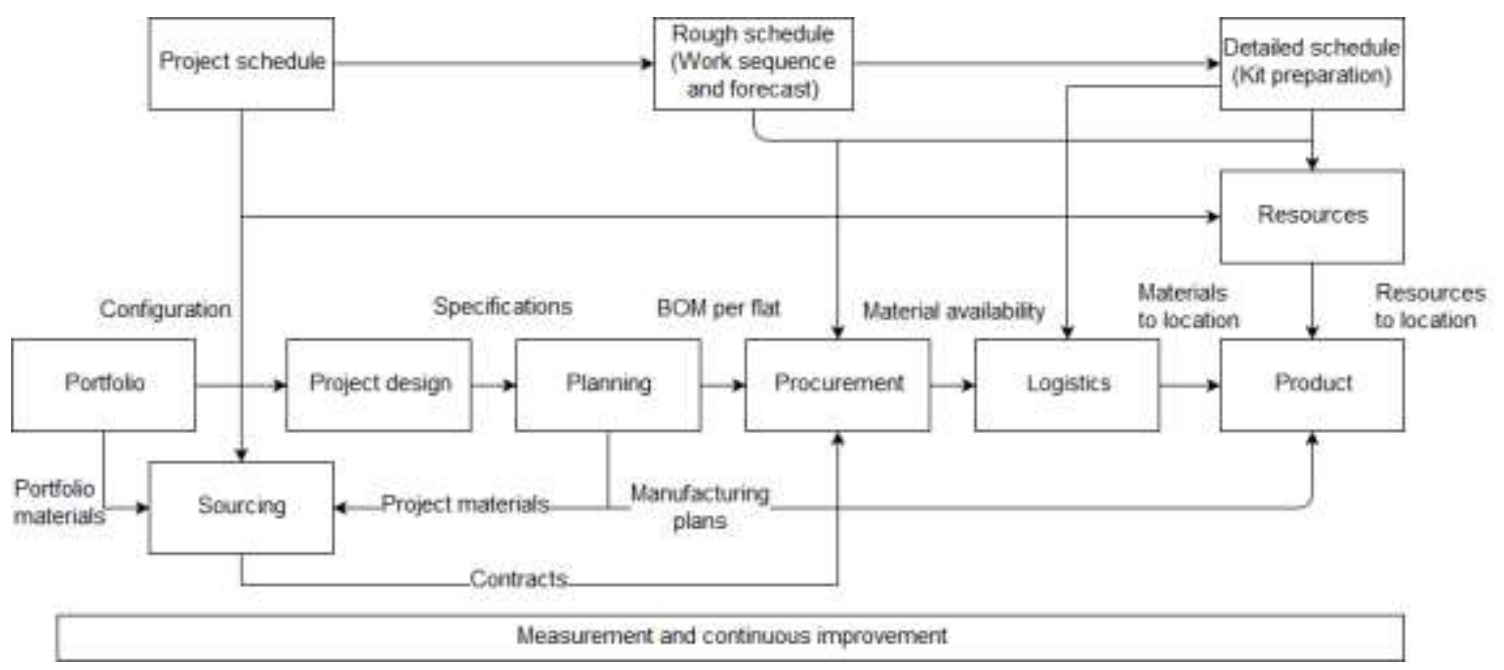

Figure 3: Production systems basic functions of the logistics provider

The external variation is reduced with the logistics solution where material availability is guaranteed. The materials arrive to the ALU two weeks before a project starts. When the materials are available and delivered to the professional who is going to use them, it is easier to measure the productivity due to reduced external variation. The total savings on materials is aimed to be $20 \%$ while it is currently $5 \%$. The aimed increase in production rate is $20 \%$ while currently it is between 0 and $10 \%$.

Table 1 illustrates the differences between shipyard and construction industries using both takt production and logistics solution. Maturity level of takt production and logistics solution is more advanced in ship cabin manufacturing.

Table 1: Differences between the shipyard and construction industries where takt production is used with logistics solution

\begin{tabular}{|c|c|}
\hline Shipyard industry & Construction industry \\
\hline ALU is next to production site & $\begin{array}{c}\text { ALU is located around } 20 \mathrm{~km} \text { from the } \\
\text { production sites }\end{array}$ \\
\hline Takt time is 40 minutes & Takt time is 1 day \\
\hline $\begin{array}{l}\text { More pre-assembly done in logistics } \\
\text { center }(20-40 \%)\end{array}$ & Pre-assembly amount is limited \\
\hline $\begin{array}{c}\text { Shorter material picking and kitting } \\
\text { time ( } 3 \text { hours) }\end{array}$ & $\begin{array}{c}\text { Material picking and kitting takes longer (1 } \\
\text { day) }\end{array}$ \\
\hline $\begin{array}{l}\text { All materials are going through the } \\
\text { ALU }\end{array}$ & $\begin{array}{l}\text { Some subcontractors still deliver materials } \\
\text { directly to the site }\end{array}$ \\
\hline
\end{tabular}




\section{DISCUSSION}

Comparing the shipyard and construction operations and using takt production with a logistics solution indicates that logistics increases the benefits that can be obtained through takt implementation. In shipyard industry, the level of implementation of takt production with logistics solution is higher than the construction industry. Moreover, centralized procurement is used in projects from both industries. According to Pesämaa et al. (2009), a systematic and holistic view is needed for successful construction management. Similarly, the logistics provider uses centralized procurement in order to reduce the material waste and cost.

The consolidation centers hold a great potential in construction industry operations. In the construction of Heathrow Terminal 5, the steel rebars were produced and materials were pre-assembled to the work packages prior to delivery on site in the consolidation centers (Doherty 2008). Based on the literature and our findings, there are opportunities to further improve the developed logistics solution in construction. Pre-assembly and precutting of the parts done in the logistics centers reduce the work load of the specialized workers on site. This brings savings to the main contractor as it can further shorten the construction time and the specialized site workers are more expensive.

Kitting reduces the time that is allocated for searching the required parts for assembly (Hua and Johnson 2010). Delivering the kits to the location where the parts are consumed increases productivity of the worker. The worker can focus on the task itself instead of searching for materials. In the construction context, a similar logistics solution to the one mentioned in this research was investigated where the workplace utilization rate was higher than the case in which logistics solution was not utilized (Tetik et al. 2018). Thus, the logistics solution which consists of centralized procurement, kitting in the ALU and JIT delivery can be used for higher productivity and quality.

Utilizing the logistics solution in takt implementation also enforces the takt sequence and schedule. Since the pre-determined schedule has to be followed and there is no material available on-site before its scheduled consuming time, there is no unplanned, off-schedule activities on-site. This reduces the rework that can be caused by unplanned activities. The control over the production process is increased.

According to our study, the design document serves several purposes in logistic processes. It informs the customer regarding the product description. It ensures that required regulations determined by the authorities are followed. Lastly, BOM can be generated for procurement and sourcing activities from the design document. It guides the employees on how to install the materials. The latter two purposes are not fully used in the construction industry. Procurement and quality issues can result from these problems.

Based on our findings, main problems encountered are related to planning and design processes. To establish the logistics service, detailed planning information is needed. However, the required maturity level in planning has not yet been reached in the construction industry. In the manufacturing industries, one main reason for generating the design model is to have accurate BOM which serves logistic processes. However, in the construction industry, the main aim is to calculate the project cost while detailed quantities per location are not available. Thus, the construction projects suffer from not being able to 
generate a detailed BOM for procurement and material delivery plan. These issues require further investigation.

\section{CONCLUSION AND FUTURE RESEARCH}

This research investigated how takt production could benefit from a proper logistics solution. The empirical analysis of shipyard and contruction industries revealed that harmful external variation for takt production can be diminished by specific logistics solution in which material picking and kitting is done in a logistic center. Implementation of takt and logistics solutions go hand in hand and therefore construction industry could learn from more mature shipyard industry when developing logistic practices to support takt production. Logistics is an important enabler for takt because material availability can be met through high quality logistics and procurement management. Moreover, having detailed planning available also enforces the takt schedule. Future research should investigate the effect of logistics in takt with utilizing case studies and focusing on more construction operations to compare and contrast the findings.

\section{REFERENCES}

Agapiou, A., Clausen, L.E., Flanagan, R., Norman, G. and Notman, D. (1998). "The role of logistics in the materials flow control process." Construction Management \& Economics, 16(2), pp.131-137.

Ala-Risku, T. and Kärkkäinen, M. (2006). "Material delivery problems in construction projects: A possible solution." International Journal of Production Economics, 104(1), pp.19-29.

Alhava, O., Laine, E. and Kiviniemi, A. (2015). "Intensive big room process for co-creating value in legacy construction projects." Journal of Information Technology in Construction (ITcon), 20(11), pp. 146-158.

Arbulu, R. and Ballard, G. (2004). "Lean supply systems in construction.” In Proceedings of 12th Annual Conference of the International Group for Lean Construction, Copenhagen, Denmark.

Bozer, Y. and McGinnis, L. (1992). "Kitting versus line stocking: A conceptual framework and a descriptive model." International Journal of Production Economics, 28(1). pp. $1-19$.

Binninger, M., Dlouhy, J., Müller, M., Schattmann, M. and Haghsheno, S. (2018). "Short Takt Time in Construction - a Practical Study." In:, 26th Annual Conference of the Int'l Group for Lean Construction. Chennai, India, 18-20 Jul 2018. pp 1133-1143.

Carter, N., Bryant-Lukosius, D., DiCenso, A., Blythe, J. and Neville, A.J. (2014). September. "The use of triangulation in qualitative research." In Oncology nursing forum (Vol. 41, No. 5).

Christopher, M. (2016). Logistics \& supply chain management. Pearson UK.

Clifford P. McCue, Jack T. Pitzer. (2000). "Centralized vs. decentralized purchasing: current trends in governmental procurement practices." Journal of Public Budgeting, Accounting \& Financial Management, Vol. 12 Issue: 3, pp.400-420. 
Dallasega, P., Matt, D.T. and Krause, D. (2013). "Design of the building execution process in SME construction networks." In Proceedings of the 2nd International Workshop on Design in Civil and Environmental Engineering (pp. 7-15). WPI.

Doherty, S. (2008). Heathrow's Terminal 5: History in the making. John Wiley \& Sons.

Ekeskär, A. and Rudberg, M. (2016). "Third-party logistics in construction: the case of a large hospital project." Construction Management and Economics. 34(3). pp. 174-191.

Frandson, A., Berghede, K. and Tommelein, I. (2013). "Takt-time Planning for construction of exterior cladding." In: Proc. 21st Ann. Conf. Int'1. Group for Lean Constr. Fortaleza, Brazil, August 31-2.

Ghanem, M. , Hamzeh, F. , Seppänen, O. and Zankoul, E. (2018). “A New Perspective of Construction Logistics and Production Control: An Exploratory Study" In:, 26th Annual Conference of the International Group for Lean Construction. Chennai, India, 18-20 Jul 2018. pp 992-1001.

Hamzeh, F., Tommelein, I., Ballard, G. and Kaminsky, P. (2007). "Logistics centers to support project-based production in the construction industry." In Proceedings of the 15th Annual Conference of the International Group for Lean Construction (IGLC 15) (pp. 181-191).

Heinonen, A. and Seppänen, O. (2016). "Takt Time Planning in Cruise Ship Cabin Refurbishment: Lessons for Lean Construction." In Proc. 24th Ann. Conf. of the Int'l. Group for Lean Construction, IGLC, Boston, MA, USA.

Hopp, W.J. and Spearman, M.L. (2004). "To pull or not to pull: what is the question?." Manufacturing \& service operations management, 6(2), pp.133-148.

Hua, S. and Johnson, D. (2010). "Research issues on factors influencing the choice of kitting versus line stocking", International Journal of Production Reseach, 48(3), pp. 779-800.

Jaillon, L. and Poon, C.S. (2014). "Life cycle design and prefabrication in buildings: A review and case studies in Hong Kong." Automation in Construction, 39, pp.195-202.

Jacobsson, M. and Wilson, T.L. (2018). "Revisiting the construction of the Empire State Building: Have we forgotten something?" Business Horizons, 61(1), pp.47-57.

Kingman, J.F.C. (1961). "The single server queue in heavy traffic." In Mathematical Proceedings of the Cambridge Philosophical Society (Vol. 57, No. 4, pp. 902-904). Cambridge University Press.

Knaack, U., Chung-Klatte, S. and Hasselbach, R. (2012). Prefabricated systems: Principles of construction. Walter de Gruyter.

Linnik, M., Berghede, K. and Ballard, G. (2013). "An experiment in takt time planning applied to non-repetitive work." In 21st Annual Conference of the International Group for Lean Construction (pp. 31-2).

Pattanaik, L.N. and Sharma, B.P., (2009). "Implementing lean manufacturing with cellular layout: a case study." The International Journal of Advanced Manufacturing Technology, 42(7-8), pp.772-779.

Pesämaa, O., Eriksson, P.E., Hair, J., (2009). "Validating a model of cooperative procurement in the Swedish construction industry." International Journal of Project Management 27 (6), 552-559. 
Pheng, L.S. and Hui, M.S. (1999). "The application of JIT philosophy to construction: a case study in site layout." Construction Management \& Economics, 17(5), pp.657-668.

Seppänen, O. and Peltokorpi, A. (2016). "A New Model for Construction Material Logistics." In Annual Conference of the International Group for Lean Construction.

Seppänen, O. (2014). "A comparison of takt time and LBMS planning methods." In Proc. 22nd Ann. Conf. of the Int'l Group for Lean Construction (pp. 23-27).

Sullivan, G., Barthorpe, S. and Robbins, S. (2011). Managing construction logistics. John Wiley \& Sons.

Sundquist, V., Gadde, L.E. and Hulthén, K. (2018). "Reorganizing construction logistics for improved performance." Construction Management and Economics, 36(1), pp.4965.

Tanskanen, K., Holmström, J. and Öhman, M. (2015). "Generative mechanisms of the adoption of logistics innovation: the case of on-site shops in construction supply chains." Journal of Business Logistics, 36(2), pp.139-159.

Tetik, M., Peltokorpi, A., Holmström, J. and Seppänen, O. (2018). "Impacts of an assembly kit logistic solution in renovation projects: a multiple case study with camera-based measurement." In Proc: 25th Annual EurOMA Conference 24-26 June 2018, Budapest, Hungary.

Tommelein, I. (2017). "Collaborative Takt Time Planning of Non-Repetitive Work" In:, 25th Annual Conference of the International Group for Lean Construction. Heraklion, Greece, 9-12 Jul 2017. pp 745-752.

Tommelein, I. and Li, A. (1999). "Just-in-time concrete delivery: mapping alternatives for vertical supply chain integration." In Proceedings IGLC (Vol. 7, p. 97).

Vatne, M. E, and Drevland, F. (2016)."Practical Benefits of Using Takt Time Planning: A Case Study." Proc. 24th Ann. Conf. of the Int'l. Group for Lean Construction, Boston, MA, USA, sect.6 pp. 173-182.

Viswanadham, N. and Raghavan, N.R.S. (1997). "Flexibility in manufacturing enterprises", Proceedings in Engineering Sciences (Sadhana Academy), Vol. 22 No. 2, pp. 135-63.

Zhao, J., Olivieri, H., Seppänen, O., Peltokorpi, A., Badihi, B. and Lundström, P. (2017). "Data analysis on applying real time tracking in production control of construction." In Industrial Engineering and Engineering Management (IEEM), 2017 IEEE International Conference on (pp. 573-577). IEEE. 